\title{
O ESTADO DEPOIS DO SOBERANO: O DIREITO E O MESSIANISMO
}

\author{
THE AFTER THE SOVEREIGN STATE: \\ THE RIGHT AND MESSIANISM
}

\author{
Jairo José GENOVA ${ }^{1}$ \\ Fernando Rodrigues de ALMEIDA ${ }^{2}$
}

Artigo recebido em: 22/07/2016

Artigo aprovado em: 21/09/2016

RESUMO: A soberania hodierna apresenta elementos extremamente ligados à uma metodologia purista derivada de uma internacionalização de legitimidade da reprodução normativa do plano interno sobre a necessidade de validade por uma plano internacional. O Soberano se relativiza ao conviver com aspectos de globalização, bem como de universalização de direitos, que de forma impositiva define limites aos sujeitos envolvidos sobre a égide do poder. A soberania é sempre buscada como uma forma a ser limitada, os tratados internacionais, a possibilidade de sanções e meios normativos, sempre estipulados por

\footnotetext{
${ }^{1}$ Graduação em Direito pela Faculdade de Direito de Araçatuba (1982) e em Ciências Contábeis pela Faculdade de Cîencias Contábeis e Atuariais de Araçatuba (1980). Mestrado em Direito pela Pontifícia Universidade Católica de São Paulo (2000) e doutor em Direito pela Pontifícia Universidade Católica de São Paulo (2007). É professor titular no curso de gradução e no programa de Mestrado do Centro Universitário Eurípides de Marília (UNIVEM) e promotor de justiça do Ministério Público de São Paulo. Tem experiência na área do Direito, com ênfase em Direito Penal, atuando principalmente nos seguintes temas: história, fundamentos e princípios do Direito Penal. Escolas e movimentos penais. Direitos fundamentais e justiça penal. Teorias do crime e da pena. Crimes em espécie e legislação penal especial.

E-mail: jjgenova@terra.com.br
}

\footnotetext{
${ }^{2}$ Mestre em direito pelo UNIVEM como bolsista CAPES/PROSUP, sob orientação de prof. Dr. Oswaldo Giacóia Junior e coorientação de prof. Dr. Roberto Bueno Pinto. Professor na instituição CESPAR (Faculdade Maringá) na disciplina de filosofia do Direito. Advogado.

E-mail: fernandordealmeida@gmail.com
} 
organizações internacionais de ponderação completam tal estrutura. A presente pesquisa não tem o intuito de esgotar o tema, apenas de observar os elementos relacionados à Soberania e sua condição mítica. O presente trabalho utilizou o método hipotético-dedutivo com uso de pesquisa bibliográfica.

PALAVRAS-CHAVE: Soberania; Messianismo; Filosofia do Direito.

ABSTRACT: Sovereignty has extremely attached to a purist methodology derived from a normative reproduction of the legitimacy of internationalization of internal order information concerning the need of validity for an international plan. The Sovereign is relativized to live with aspects of globalization, as well as universal rights which form of imposing sets limits to the subjects involved under the aegis of power. Sovereignty is always sought as a way to be limited, international treaties, the possibility of sanctions and regulatory means, always stipulated by international organizations weighting complete such a structure. This research is not intended to exhaust the subject, only to observe the elements related to sovereignty and its mythical status. This study used the hypotheticaldeductive method with the use of literature.

KEY WORDS: Sovereignty; messianism; Philosophy of law. 


\section{Introdução}

A estrutura normativa passa por crises, derivadas do próprio modelo ideológico que já foram apresentados, a critica schmittiana aparece muito forte em tal ponto, em que situações limites aparecem incorrigíveis pela estrutura normativa.

Nesse ponto, encontramos um segundo risco, além da estrutura normativa agir de forma a inverter a historia, produzindo corpos dóceis a partir da disciplina, a crítica a tal modelo tende a se basear em uma arriscada estrutura decisionista que vê as crises de estabilidade do conceito estatizado do soberano como uma possibilidade de interferência por meio da ditadura. O que significa uma violência de mão dupla, além da impositividade ideológica, a força biopolítica agindo diretamente sobre os corpos, não apenas para a existência do soberano, ou seja, o que traz de volta ao corpo a condição de homo sacer ${ }^{3}$, mas pela exclusão de sujeitos, a partir de uma decisão.

Para isso, resgata-se o pensamento de Walter Benjamin, como uma antítese não ao normativismo ou ao decisionismo, mas ao modelo de violência como um todo. A violência pura que buscar-se-á a partir do referenciado autor, tratará de uma alternativa ao Soberano como inversão histórica, colocando de forma patente sua origem para sua desconstrução e, consequente, reestruturação a partir de um nascimento da estrutura social a partir da própria opressão.

Ao observarmos a estrutura normativa se utilizando de uma estrutura decisionista como remédio as crises democráticas, como, por exemplo, guerras injustificadas, ou com seu telos obscurecido, como é o caso da Guerra contra o Iraque e a imposição de universalidade em razão do poder, podemos observar que há um espaço de anomia se formando dentro da própria normalidade.

Não se abre mão do normativismo, porém se utiliza meios decisionistas sem que se declare, necessariamente um estado de Exceção, entrementes os povos sofrem excepcionalidades

\footnotetext{
${ }^{3}$ Nas notas do tradutor constantes na obra "Homo Sacer - o poder soberano e a vida nua I", Henrique Burigo explica: "Homem sacro é, portanto, aquele que o povo julgou por um delito; e não é lícito sacrificá-lo, mas quem o mata não será condenado por homicídio; na verdade, na primeira lei tribunícia se adverte que "se alguém matar aquele que por plebiscito é sacro, não será considerado homicida”. Disso advém que um homem malvado ou impuro costuma ser achado de sacro" (BURIGO in AGAMBEN, 2007, p. 196).
} 


\section{$2 \mathrm{O}$ mito do soberano e sua existência sobre o sacrifício}

Há uma relação ideológica que se dá na estrutura contemporânea de soberania: a manutenção da globalização e do elemento normativo que define o soberano a partir de normas pressupostas, não declaram a exceção como método de manter os direitos impostos, como os direitos humanos, como fundamento da manutenção do poder disciplinar presente na ideologia interna das sociedades, entretanto, existem métodos decisionistas, que aplicam suspensões de direito dentro da normalidade.

A tradição dos oprimidos ensina-nos que o $<<$ Estado de Excepção>> em que vivemos é a regra. É-nos preciso elaborar uma concepção da história que corresponda a tal estado. A partir daí constataremos que a nossa tarefa consiste em criar um verdadeiro estado de exceção; e assim tornar-se-á melhor a nossa posição na luta contra o fascismo (BENJAMIN, 1992, p. 161).

Assim como em Agamben, o trabalho de Walter Benjamin observa o que ele chamará de "Mera Vida" como o corpo que se projeta a partir de sua desconfiguração política, entretanto, em tal conceito, há uma diferença essencial, qual seja, a eterna repetição da função mítica que acompanha a mera vida. O mito da violência significa que há um ciclo entre a história dos oprimidos, sempre há o sacrifício envolvendo os corpos em relação ao mito criado. Como pode ser observado anteriormente no presente trabalho, não há como desvincular o soberano moderno do mito segregacional envolvendo a politização da vida nua, ou seja, sempre que houver um mito para determinação do poder, há, por conseguinte, a violência agindo sobre os corpos, ou seja, "a violência mítica é violência sangrenta exercida, em favor próprio, contra a mera vida; a violência divina e pura se exerce contra toda a vida, em favor do vivente. A primeira exige sacrifícios, a segunda os aceita" (BENJAMIN, 2011, p. 151).

Para Benjamin é necessário o resgate histórico para a definição dos padrões entre os oprimidos e os vencedores, o que significaria dizer, que nessa raiz mítica que delimita o espaço de poder do direito, sempre houve um ciclo em que vencedores, da mesma gênese definiram os mitos a partir de sua essência para a opressão.

A problematização da fragilidade da interpelação do corpo como sujeito e seu entendimento como objeto original pela força do padrão ideológico se dá 
no momento em que se possibilita a revogação normativa, ou seja, retirando do sujeito de direito seu quadro normativo e o deixando a mercê da ideologia sem violência seu conceito paira em um limbo que o reduz a corpo, logo não é garantido o processo de humanização sem a força normativa. Humanização pela produção de verdade ideológica do que significa o ser humano - definida como a reestruturação do corpo a sua condição pura leva o ente social a posição de corpo sem significado dentro do sistema social, isso, partindo da própria produção ideológica do conceito de ser humano, ou seja, o consenso (abstrato) que sua morte não pode ser relativizada, tampouco sua vida (existência).

Porém, retirada sua condição valorativa sujeita ao biopoder ${ }^{4}$, exercido pelo soberano, o que resta ao corpo é apenas o corpo, uma objetivação biológica livre de abstração ideológica. E, da mesma forma, retirado seu conceito de humanidade, nada resta ao corpo do que a vida nua. Para isso, pela visão de Giorgio Agamben, reduz-se o conceito do corpo apenas aquilo que ele é, livre da intervenção do poder e, consequentemente, livre de sua razão cultural ideológica, assim, o que nos resta é um corpo sem legitimidade da estrutura política.

Agamben revela aquilo que, disseminando-se por seus textos posteriores, permitiria esquadrinhar o pano de fundo de sua filosofia: o projeto de uma filosofia da vida como uma filosofia que vem. Na base de seu projeto, encontra-se a problematização, desde logo política, da vida como objeto do poder - da operação de poder que, a fim de engendrar uma produção da vida humana e politicamente predicada (bios), toma por ponto de inflexão o vivente a fim de aplicar-se sobre ele, excluindo de seu âmbito a vida animal (zoé). Tal conceito encontra-se presente em textos como L'immanenza assoluta (2005) e Homo sacer:

\footnotetext{
${ }^{4}$ A função do símbolo atribuído pelo conhecimento do conceito de ser humano integrado na sociedade, portanto, trata-se da força da capacidade humana, intrínseca a existência do ser, definido, consequentemente, em razão de sua posição como incluso na sociedade - inicialmente como proletariado - e aparente em sua função intrasistêmica, que, por razão da complexidade da estrutura social se estabiliza em determinada posição social e então se relaciona e se comunica - por conseguinte se entende pelo norte da ideologia da cultura - de acordo com sua função e característica simbólica. De toda forma, essa condição irrestritamente humana é traduzida como estrutura política, ou seja, os instrumentos ideológicos necessitam da posição do ser humano como cultura baseada em sua posição social (o valor econômico de sua função) para reduzir os riscos da falência do liberalismo. Tal estrutura pode ser entendida por Biopoder que Fonseca (2002, p. 207) traduz "como o conjunto de mecanismos pelos quais aquilo que na espécie humana constitui seus traços biológicos fundamentais vai poder entrar no interior de uma política, de uma estratégia política, de uma estratégia geral de poder. Em relação à tecnologia disciplinar, esse conjunto de mecanismos (em que se constitui o biopoder) define um outro modo de agenciamento do espaço, especifica uma forma diferente da normalização e singulariza um novo "corpo" enquanto objeto e sujeito da estratégia de poder representada pela biopolítica".
} 
o poder soberano e a vida nua I (2007). Eis o desenvolvimento que Agamben, passando por Foucault, retoma da fundação aristotélica da pólis grega (CORRÊA, 2010, p. 337).

Pois bem, reduzido em sua bios e reestruturado em sua função de zoé, o corpo passa a não ser mais parte do sistema social, afinal, conquanto tenha se afastado do aparelho ideológico agora não tem mais função útil no biopoder.

À vida nua e aos seus avatar no moderno (a vida biológica, a sexualidade, etc.) é inerente uma opacidade que é impossível esclarecer sem que se tome consciência do seu caráter político; inversamente, a política moderna, uma vez que entrou em intima simbiose com a vida nua, perde a inteligibilidade que nos parece ainda caracterizar o edifício jurídico-político da política clássica (AGAMBEN, 2007, p. 126).

A decisão, portanto, da existência da vida nua cabe exclusivamente ao poder soberano, uma vez que é este quem tem legitimidade para ser Estado e, portanto, nada mais tem que o controle dos aparelho ideológicos e da forma de cultura. Desta forma, o conceito de vida nua está diretamente ligada ao conceito da função que o Estado dá àquele corpo, independentemente de sua existência simbólica.

A definição da vida nua, como se observa, como mito fundador do soberano e, consequentemente a estrutura hodierna de soberania, não foge a regra de uma estrutura em que os vencidos se manifestam de maneira a interferir na história para que os sujeitos se apreendam em aparelho ideologicamente estruturados como método de disciplina para a manutenção de poder.

Porém, a estrutura normativa, que faz parte da estatilização $0^{5}$ de fundamentação de afastamento aparente do mito no soberano contemporâneo apresenta-se com inevitáveis crises, e o discurso decisionista, bem como

\footnotetext{
${ }^{5}$ A opção de tratar o processo ideológico de velamento da gênese da Soberania pelo neologismo "estatilizar" se deu a partir da necessidade de diferenciação do verbo transitivo "estatizar". Não se trata, no presente trabalho, de adjetivar o substantivo "Estado", a fim de dar a ele uma característica genealógica, mas sim, observar um processo ideológico de centralidade dessa genealogia no conceito político e jurídico de Estado. Dessa forma aquilo que se refere à ideologia do Estado sobre sua gênese é diretamente relacionado àquilo criado para ser propriedade - ou sujeição - ao conceito jurídico-político de Estado, por conseguinte, a ideologia de gênese centralizada no instituto torna-se um elemento "Estatal". O processo de velamento ideológico próprio da categoria jurídico-política do Estado, portanto será tratada pela união entre "Estado" e "Estatal", de forma a ser chamada de "Estatilização".
} 
ações soberanas apresentam-se cada vez mais comuns nas estruturas políticas internacionais.

Dessa forma, é clara a necessidade do discurso benjaminiano para a busca do que poderemos chamar de "violência pura", que mais a frente trataremos, mas antes de tudo, entender o porquê do resgate do autor em comento para o combate ao modelo schmittiano, que, de certo, apresenta o problema da soberania em que vivemos, uma vez que, definitivamente, apresenta-se como decisões excepcionais dentro de uma normalidade normativa, ainda como formula de mascaramento do mito que revela a história dos vencedores.

Neste momento, não é irrazoável reconhecer um diálogo entre Benjamin e Carl Schmitt. Como já mencionado, o primeiro coloca-se nas fileiras da tradição dos oprimidos, enquanto o segundo, no período, talvez, seja o representante máximo do arcabouço teórico jurídico-político, vindo a tornar-se o grande jurista do Reich, portanto, colocando-se a serviço da tradição dos vencedores (RAMIRO, 2013, p. 244).

É nesse sentido que busca-se a desvinculação de qualquer coordenada mítica para que o Soberano possa ser desvinculado da violência. Ou melhor, o espaço de poder vincula-se à violência a partir de estruturas normativas, estatilizadas, deforma que toda a história dos oprimidos, em termos benjaminianos, refere-se a um elo inseparável entre interesses dos vencedores relacionados com a capacidade de poder e atuação violência sobre os corpos.

A atuação do soberano é claramente mítica, como já discutido, não há como desvincular a gênese soberana da politização do corpo em seu espaço de anomia, o que funciona, consequentemente, como a definição dos limites da força violenta utilizada pelo poder.

Isto significa dizer, que a necessidade de politização da vida nua é justamente a manifestação do poder como violência necessária para a manutenção da estabilidade de um conceito de soberania. Não há como manter uma estrutura de poder sem a possibilidade de violência direta sobre os corpos, para os modelos jurídico-politico que se definem a partir das sociedades vinculadas aos padrões ideológicos de formação de corpos dóceis, em outras palavras aos sujeitos vinculados à tradição dos oprimidos.

Tal tradição que encontramos o fundamento do eterno ciclo do poder como estrutura violenta, por mais que o soberano contemporâneo se 
justifique a partir de modelos jurídicos, de imposição de direitos universais, ou de positivação de dignidade, os mesmos meios que permeiam a opressão na história se repetem, não de forma fenomenológica, mas de forma a operar na docilização dos presentes em um estatuto social e, por conseguente, o risco destes de deparar-se com a inviabilidade da vida nua como consequência de risco a gênese soberana.

Para Agamben, a constituição da esfera política da soberania consistente no direito de vida e morte, direito de fazer morrer ou deixar viver, é o fato jurídico primordial, que tem a exceção como "estrutura originária, naquela o direito se refere à vida e a inclui em si através de sua própria suspensão". Por causa disso, o verdadeiro antípoda de Kelsen e Schmitt é a filosofia de Walter Benjamin, para quem a violência é pensada como uma figura completamente resistente às estratégias colonizadoras do direito: pensar uma violência pura equivale a pensa-la emancipada, sem relação com as categorias do direito, já que o direito, tal como se configura sob a forma histótica dos Estado-Nação, constitui o dispositivo que assegura paradoxalmente, ao mesmo tempo, a dominação e a inclusão, sendo, portanto, desde a origem, um dispositivo sangrento (GIACÓIA JUNIOR, 2014, p.259-260).

O soberano deve-se fundar em uma estrutura de politização do corpo para sua existência, mas é na estrutura do Direito que encontra sua legitima manifestação de poder, veja-se que agora, a partir de Benjamin, podemos relacionar toda a estrutura ideológica de um sistema social a aplicação do Direito.

O Direito manifesta-se de forma vinculante aos atos dos corpos incluídos no meio social, isso, por si, já qualifica aqueles corpos excluídos do sistema soberano como impedidos de serem punidos, mas ao mesmo tempo, de definirem-se como direitos próprios, por conseguinte, temos a devinição da sacralidade do corpo.

Porém, aqueles incluídos no modelo de definição estatuída da soberania devem sua permanência a violência exercida pela coerção do direito. Que apresenta-se como a ferramenta legitimada de violência estatal.

A ideologia, por si, é uma violência soberana, uma vez que inverte a história e mantém os corpos em uma disciplina categorizada por suas próprias vontades, ou como pode ser da mesma forma chamada, a partir da "liberdade imposta". Porém é no direito que as liberdades são limitadas e gera-se a opressão frente ao próprio direito. 
A liberdade manifesta-se com um caráter universal, porém a retirada da liberdade é o primeiro estágio de manutenção do poder como violência dentro de uma forma jurídica. Os oprimidos pelo direito necessitam de tal opressão para que convivam com as antíteses apresentadas pelos modelos ideológicos. Ou seja, se há capital, há desigualdade, se há desigualdade há violência social, por conseguinte, há necessidade de estruturação punitiva para controlar tal violência social. Em outras palavras, é necessária a aplicação de violência do direito para combater o resultado da imposição violenta da ideologia sobre os corpos. Isso significa dizer que o poder gera violência para a manutenção da própria violência, como fórmula de manutenção da gênese do poder soberano.

Longe de inaugurar uma esfera mais pura, a manifestação mítica da violência imediata mostra-se, em seu núcleo mais profundo, idêntica a toda violência do direito, e transforma a suspeita quanto ao caráter problemático dessa violência em certeza quanto ao caráter pernicioso de sua função histórica, tornando tarefa sua abolição. Tal tarefa suscita, em última instância, mais uma vez, a questão de uma violência pura, imediata, que possa estancar a marcha da violência mítica (BENJAMIN, 2011, p. 150).

Se há existência do mito, há necessidade de aplicação violenta do direito, isto porque o mito deve funda-se como algo aquém da capacidade de observação daqueles envolvidos no mitologema.

Não há como sustentar um mito, que gera a violência original daquele tempo, se há a consciência da existência de uma faculdade mítica aplicada à sociedade. Por certo, se há um mito de fundação, este deve ser visto como uma realidade ou, como no caso do soberano hodierno, deve ser afastado de seu mito original o centro de fundação, no caso, o corpo matável, que servirá posteriormente, como instrumento final da exceção.

Afastado a aparente consciência a respeito do mito, substitui-se por outro conceito a ser determinado por uma metodologia ideologista, que no caso apresenta-se como uma estatilização do fundamento de origem do poder, que, por consequência, legitima a norma, de forma que não apenas de modo punitivo se entende o Direito, mas sim como uma categoria viabilizadora dos conceitos sociais, ou ainda, como uma possibilidade de existência de uma ordem.

Dessa forma toda violência é empregada a partir de um mascaramento ideológico, o Direito se vale de uma estrutura de reprodução violenta para produzir uma dependência dos oprimidos por aquele direito pelo próprio 
caráter do direito.

Como observado no tópico anterior, é na relação de exclusão que o mito se reproduz, a historia dos vencedores se fundam no mito sacrificial e na necessidade de relação com um bando que gera o sentimento de abandono no banido, o que significa, portanto, colocar tal corpo em um agrupamento que o exclui, induzindo-o a se diferenciar, em um ciclo vicioso e perpétuo de sentimento de abandono e da presença da vida nua sobre sua inclusão social.

A figura do banido era, na antiguidade germânica, o Friedlos, o "sem paz", teria seu fundamento na paz (Fried) assegurada na comunidade, da qual a proscrição o excluiria. Tratava-se, pois, de um caso de exclusão includente, ao qual o ordenamento jurídico se aplica integralmente, por meio de sua própria suspensão - a instituição do bando mantém o proscrito capturado fora do ordenamento, na medida em que a aplicação (incidência) da decisão soberana consiste precisamente na exclusão e suspensão da lei e da paz, fazendo coincidir, num mesmo ato, suspensão (exclusão) e aplicação (inclusão) (GIACÓIA JUNIOR, 2008, p. 38).

Enquanto houver um mito por traz da existência do direito, o direito se autoreproduz, de fato, dentro de um sistema social, a partir da imposição normativa, que pode ser resgatada a partir da história dos vencedores.

De tal forma que, o normativismo pode ser substituído por qualquer outro modelo de direito que já tenha agido sobre os vencidos, seja, por exemplo o poder mítico divino da monarquia, ou a fundação de Roma sob o mito de Rômulo e Remo.

Temos sempre uma justificativa anterior à própria origem do mito para fundamentar a atuação da opressão, sempre pela forma Direito, ou seja, pela imposição de forma para a manutenção de uma estrutura ideológica, para que, assim, a propria vinculação dos oprimidos pela força por eles sofrida se torne um ciclo vicioso, que o vencido sofre e necessita em razão da necessidade de permanência em tal sistematização.

Toda violência como meio é ou instauradora ou mantenedora do direito. se não pode reivindicar nenhum desses predicados, ela renuncia por si só a qualquer validade. Daí resulta que toda violência como meio, mesmo no caso mais favorável, participa da problemática do direito em geral. E mesmo que, nesta altura da investigação, não se possa enxergar com certeza o alcance 
dessa problemática, o direito, depois do que foi dito, aparece sob uma luz ética tão ambígua, que se impõe naturalmente a pergunta se não existiriam outros meios, não-violêntos, para a regulamentação dos interesses humanos em conflito. A pergunta obriga, sobretudo, a constatar que uma resolução de conflitos totalmente não-violenta jamais pode desembocar num contrato de direito (BENJAMIN, 2011, p. 11).

Entretanto, a violência como meio de determinação dos corpos para que sejam limitados e, ao mesmo tempo, dependentes dos meios violentos para a proteção perante o estado se esvanece perante o próprio modelo de Direito. Por esse motivo, os modelos de poder na história tanto se modificam, porém sem perder sua essência tradicional de quem são os vencedores.

O grande problema é que, mesmo ocorrendo a cíclica falência dos métodos de poder, o discurso dos vencedores permanece sobre outro aspecto ideológico, ou seja, no momento de uma situação de limite, ou melhor, à crise quanto a estruturas de poder, outro mito tende a se formar para garantir interesses ainda dos vencidos.

É justamente em tal ponto que encontramos a situação da soberania moderna, diante da estrutura da democracia liberal, as instituições encontramse em crise, justamente utilizando-se de meios que fogem à finalidade proposta nos meios de produção ideológica, para isso, logo se vê discursos em reação a tal modelo.

No momento em que vivemos encontramos o discurso conservador retornando ao ambiente político de debates como fórmula de resolução aos conflitos que a democracia vem se mostrando insuficiente dentro dos modelos de Estado em que nos deparamos.

Em um setor interno, ou seja, no modelo social brasileiro, diante de crises democráticas, ligadas diretamente à representação, observamos o resgate a um discurso de busca de ditadura, ou seja, da legitimação de um indivíduo como sustentação de um contradiscurso de um Estado em Crise.

É justamente em tal ponto que se encontra a necessidade de rompimento com a violência, o ciclo novamente se coloca sobre a crise, outro mito se funda, com a mesma essência, que traz o mesmo patamar de violência contra a violência que já não se sustenta nos corredores sociais.

Em Benjamin a violência do Direito sabota o próprio direito. A preocupação é que se possa retirar o mito e não apenas substituí-lo por outro, 
ou seja, como citado anteriormente, são nesses termos que o autor roga que os oprimidos fundem sua própria exceção, não mais fundada em um mito, mas o rompimento com a crise e com a violência na busca de uma extirpação de meios de inversão histórica.

Ora, mas para que haja rompimento, é necessário que haja violência. Para isso Benjamin propõe o que chamaremos de violência pura, também tratada pelo autor em testilha como violência divina, que tem o caráter de aniquiladora da função mítica do Direito, ou seja, existe a violência que rompe com toda a estrutura do Direito, não sendo fundada em um mito, porém em uma oposição aos fundamentos de tal análise.

Justamente os efeitos dessa crítica que se esforça por provar a efetividade de uma "violência pura" são intolerá veis para jusfilósofos como Carl Schmitt e Hans Kelsen. Se o segundo simplesmente exclui a violência, e com ela a política, dos limites de uma racionalidade puramente jurídica, a teoria schmittiana do estado de exceção constituiria, segundo Agamben, um esforço para capturar a ideia benjaminiana de violência pura na figura de uma anomia inscrita no coração do nómos, sendo a exceção uma modalidade de aplicação do ordenamento jurídico justo por meio de sua suspensão, uma situação excepcional em que a lei se aplica, ao suspender-se num estado de pura vigência, mediante uma auto-suspensão decidida e instaurada pela vontade soberana (GIACÓIA JUNIOR, 2014, p. 268).

Baseando-se no modelo messiânico da violência, Walter Benjamin busca uma estrutura de possibilidade de uso da violência sem que a estrutura a ser rompida mantenha os mitos fundadores de elementos de poder.

Para isso a purificação da violência significa a oposição a violência mítica que exerce domínio sobre os corpos, ou em termos do autor, os reduzindo à mera vida, já em uma violência pura, à uma análoga teológica, a absolvição da culpa do homem para que permita sua própria vivencia é a essência da estrutura de uma violência que rompe com a estrutura do Direito a fim de que os homens possam utilizar de uma autonomia.

Além do conceito de consciência de classe, o resgate da história que deflagra que sempre houve os mesmos oprimidos em razão dos opressores, que não difere em nada do modelo contemporâneo de soberania, com exceção dos meios ideológicos utilizados para a manifestação do poder, Benjamin, busca na 
estrutura divina uma racionalização da consciência a partir do resgate da história.

A busca é por um rompimento estrutural, ou seja, um movimento violento, que não se funde em um mito sequer, mas, a expiação da culpa, ou seja, a possibilidade da autonomia das vontades dos vencidos, diferente, por exemplo da relação mítica que traz à expiação o conceito de culpa.

Se a violência mítica é instauradora do direito, a violência divina é aniquiladora do direito; se a primeira estabelece fronteiras, a segunda aniquila sem limites; se a violência mítica traz, simultaneamente, culpa e expiação, a violência divina expia a culpa; se a primeira é ameaçadora, a segunda golpeia; se a primeira é sangrenta, a divina é letal de maneira não sangrenta (BENJAMIN, 2011, p. 150).

É justamente essa possibilidade de inauguração de um rompimento em que os oprimidos se manifestem a partir de sua própria condição de sofrimento que se poderia chegar a um modelo de poder sem violência, ou seja, a desvinculação do mito como fórmula de manutenção ideológica e de estruturação de disciplina.

A violência pura tem seu caráter revolucionário, justamente pela presença da violência, ou seja, toda revolução significa um rompimento com um quadro estrutural de poder em determinado espaço-temporal, todavia, trata-se de um poder sem a expiação conjugada com a culpa, em termos dos conservadores da teologia política, como Joseph d'Maistre e seu providencialismo.

Não se trata, de forma alguma, de um pessimismo antropológico, que necessita do controle sangrento das massas derivadas da impossibilidade de controle de suas vontades, uma vez que em toda a história dos oprimidos, suas vontades estiveram definitivamente vinculadas com a força violenta do mito, ou seja, pelo Direito, que os segrega e os torna dependentes de sua atuação.

A busca da referência messiânica em Benjamin tem um caráter de substituição da punição pelo perdão, ou seja, "essa violência - identificada com a greve geral proletária de Sorel - seria a verdadeira realização do socialismo, no sentido autenticamente marxiano, pois não mais institui ou assegura a aplicação do direito, mas o depõe, juntamente com sua realização sob a forma do Estado" (GIACÓIA JUNIOR, 2014, p. 269).

Benajamin, portanto, trabalha para além da consciência de classe, uma vez que a violência é existente como forma de revolução, entretanto sem o 
condicionamento aos meios de busca mítica de fundamentação.

Mais do que a união entre classes, é o resgate histórico da consciência, a busca de um messianismo presente na história, em que todo aquele que enquadra-se como oprimido no tempo tem à sua disposição a revolução, mas sem necessariamente, o derramamento de sangue, mas com a apreensão da relação entre soberania, direito e violência, o que consequentemente apresentase, sempre como fórmula de poder.

O poder, por sua vez, deve apresentar-se como um poder messiânico, que não apresenta-se como imposição de poder, mas como abertura de consciência e descentraçlização da ideologia, permitindo os conceitos que se devem apresentar como necessários. Caso seja a liberdade, que seja a liberdade de fato.

Longe de inaugurar uma esfera mais pura, a manifestação mítica da violência imediata mostra-se, em seu núcleo mais profundo, idêntica a toda violência do direito, e transforma a suspeita quanto ao caráter problemático dessa violência em certeza quanto ao caráter pernicioso de sua função histórica, tornando tarefa a sua abolição. Tal tarefa suscita, em última instância, mais uma vez, a questão de uma violência pura, imediata, que possa estancar a marcha da violência mítica. Assim como em todos os domínios Deus se opõe ao mito, a violência divina se opõe à violência mítica. E, de fato, estas são contrárias em todos os aspectos. Se a violência mítica é instauradora do direito, a violência divina é aniquiladora do direito; se a primeira estabelece fronteiras, a segunda aniquila sem limites; se a violência mítica traz, simultaneamente, culpa e expiação, a violência divina expia a culpa; se a primeira é ameaçadora, a segunda golpeia; se a primeira é sangrenta, a divina é letal de maneira não-sangrenta (BENJAMIN, 2011, p. 35).

A apresentação de uma desconstrução do Soberano a partir de um poder messiânico é intrínseco a condição de determinação sobre a gênese do Soberano contemporâneo. Não há diferença estrutural sobre a genealogia do poder e da violência, sempre há relação com a necessidade de fundação sobre um mito, por conseguinte, uma estruturação ideológica previamente aparelhada e a vinculação da punitividade com a necessidade de condicionamento dos sujeitos a partir de sua dependência à punitivadade. Em outras palavras, o mesmo que é violentado pelo poder, graças à estrutura mítica a qual é enquadrado, depende da mesma violência. 
Não é a intensão do presente trabalho afirmar um poder messiânico como a esfera última de resolução dos problemas da violência derivada do poder, ao contrario, a intensão da exposição de uma possibilidade de violência pura, é a determinação final da possibilidade de localização da genealogia do soberano contemporâneo.

O Soberano existe e manifesta-se ainda nos tempos de hoje, por mais que a globalização ou o normativismo o relativizem. O soberano existe uma vez que sua genealogia aponta para seu nascimento na politização dos corpos que são envoltos pelo seu poder.

Por mais que em um purismo metodológico, não haja como determinar o Soberano em seus termos originários, ou mesmo que a soberania seja uma contradição em termos perante a sociedade internacional, o aprisionamento dos sujeitos de direito dentro de um quadro normativo que determinem sua existência enquanto corpos politizados relaciona-se diretamente ao Soberano, ainda que não se manifeste personalizado, ou aparentemente personalizado, todavia, as instituições que se beneficiam da estrutura de poder, existem personalizadas em seus dirigentes.

\section{$3 \mathrm{O}$ mo(vi)mento político do ponto de vista marxista}

A fundamentação da existência do soberano a partir de um mitologema sempre ligado ao sacrifício afasta o poder da centralização no corpo sobre sua finalidade, mas encontra essência na estatilização, por conseguinte, criando de forma ideológica um telos Soberano que o da legitimidade de criação de fundamento aos corpos, sob a estática da vida nua.

A desvinculação da violência do poder, até o presente momento do trabalho, se traduz em uma busca de uma localização genealógica da soberania, a fim de que se encontre o lugar da violência e se busque uma força de rompimento estrutural com as bases do sacrifício para que possa se chegar a algum ponto em que se volta ao centro da autonomia dos corpos, para que os conceitos que determinam a validade da individualização não sejam mais um processo ideológico, tampouco um processo político de humanização.

Como observamos neste capítulo, na gênese soberana encontramos a vinculação de seu poder na possibilidade de violência presente no sacrifício necessário aos corpos, ou seja, a necessidade de politização da vida nua, a fim de determinar com exatidão os limites dos sujeitos envolvidos no sistema social. 
Por conseguinte, o elo entre o poder e a violência encontra-se justamente na existência da soberania que, por sua, vez tem a necessidade de reproduzir-se material e ideologicamente nos sujeitos agregados em seu seio.

Entretanto, no presente trabalho, para que haja um fim passível de discussão para um desenvolvimento acadêmico útil, necessita-se, finalmente, observar a possibilidade de um Estado para além do Soberano, ou seja, ao apresentar-se a conclusão que é no Soberano que repousa a politização da vida nua e a necessidade de sacralidade no mito de fundação, como é possível iniciar um debate sobre o definhamento da estrutura de poder e, ao mesmo tempo, como é a preocupação de Walter Benjamin, não produzir uma revolução que se consista em uma violência que reproduz os elementos da história dos vencedores, mas que produza, de fato, um estado de exceção sob a ótica dos historicamente vencidos.

Para isso, neste ultimo tópico resgata-se, como no inicio da discussão do capítulo, o ponto de vista marxista, para observar uma possibilidade de um Estado que possa se separar da sociedade civil, ou seja, em que a autonomia dos corpos não necessite de politização, tampouco de sacralidade em seus conceitos ideológicos de apreensão.

Em Karl Marx, podemos encontrar duas linhas de pesquisa sobre uma crítica ao estado moderno. A primeira, presente na obra "ideologia alemã " (MARX; ENGELS, 1998), que relaciona diretamente a formação do Estado historicamente definido ao desenvolvimento da propriedade privada. A segunda, por sua vez, busca a gênese do Estado sob o prisma da Revolução Francesa.

Quanto à vertente primeira, que nos importa para entender que a separação da sociedade civil e do Estado é o fundamento necessário para que haja o desvelamento da soberania a partir de seu próprio cerne, se observa que a propriedade privada se torna elemento constitutivo do Estado, ou seja, se torna institucionalizada para garantir os meios de produção e a manutenção da divisão do trabalho, estatilizando a finalidade do poder como a de garantidora das instituições.

Nos modos de produção pré-capitalistas, a propriedade possuía um caráter comunitário e não se constituía ainda de forma privada e individual. A formação do modo capitalista de produção e a divisão do trabalho por ele determinada impõem-se sobre o aspecto coletivo desfrutado pela propriedade nas comunidades pré-modernas. $\mathrm{O}$ advento da propriedade privada confunde-se com a reorganização social 
e a reconfiguração do trabalho demandadas pelo capitalismo emergente (POGREBINSCHI, 2009, p. 39).

A ideia de propriedade privada como fundamento ideológico para a formação do conceito de Estado não se confunde com a formação do poder soberano. A formação mítica do soberano dá-se pela fórmula sacrificial enquanto a formação do Estado se dá pela manutenção dos ideários sociais após a definição do espaço de poder.

$\mathrm{Na}$ propriedade privada como fórmula de fundamento de estado, encontra-se uma necessidade de institucionalização de uma prática de segregação, como observado por Marx, a propriedade privada relaciona-se desde o inicio com a noção de separação funcional, ou seja, por gestos de diferenciação social.

Portanto, aqui temos a relação necessária entre a fundação do Estado e do Soberano, a partir do mito sacro, o soberano tem o poder de definir o corpo como um espaço de anomia para que seu quadro ideológico seja mantido de forma disciplinar e reguladora, da mesma forma, a gênese do estado se da no sacrifício, ou seja, a partir da apropriação do corpo, como na escravidão ou no pátrio poder, o poder se manifesta de forma ideológica, sem necessidade de controle externo, ou seja, a institucionalização da propriedade privada afirma o sacro e forma o soberano em sua manutenção.

Como é possível observar, o conceito de propriedade privada, em Marx, relaciona-se intimamente com os gestos de diferenciação estatilizados, isso significa dizer que a partir da noção de propriedade e da necessidade de proteção a tal direito de propriedade o Estado necessita institucionalizar a propriedade em conceitos de atividade e produção, ou seja, primeiro quanto a atividade, função derivada do sacrifício humano, qual seja, a utilização do corpo como objeto, para então existir a valoração necessária e a divisão social do trabalho. Por conseguinte a propriedade privada material classifica-se como o produto das relações de trabalho, garantidas pelo estado para que a divisão do trabalho permaneça em forma de propriedade.

Mais do que isso, significa dizer que a propriedade privada, seja em caráter de atividade ou de produto da atividade, vinculam a finalidade da sociedade civil a instituição estatal que, por outro lado contradiz as atividades sociais do conceito de Estado.

Esta divisão do trabalho, que se implica todas essas contradições, e repousa por sua vez na divisão natural do trabalho na família e 
na separação da sociedade em famílias isoladas e opostas umas às outras - essa divisão do trabalho encerra ao mesmo tempo a repartição do trabalho e de seus produtos, distribuição desigual, na verdade tanto em quantidade quanto em qualidade. Encerra portanto a propriedade, cuja primeira forma, o seu germe, reside na família onde a mulher e os filhos são escravos do homem. A escravidão, certamente ainda muito rudimentar e latente na fampilia, é a primeira propriedade, que aliás já corresponde perfeitamente aqui à definição dos economistas da força de trabalho de outrem. Assim, divisão do trabalho e propriedade provada são expressões idênticas - na primeira se enuncia, em relação à atividade, aquilo que na segunda é enunciado em relação ao produto dessa atividade (MARX; ENGLES, 1998, p. 27-28).

Nessa toada, entende-se que a contradição presente entre o conceito de sociedade civil e Estado remetem-se diretamente a existência do poder soberano por traz dos conceitos ideológicos presentes na utilização da violência como fórmula de manutenção do poder.

A estrutura da propriedade privada como método de diferenciação entre sujeitos, mostra-se justamente como um resultado da sacralidade presente na manutenção da existência do estado. Ao relacionarmos a necessidade do rompimento com o Estado, necessariamente, referimo-nos ao rompimento com a violência presente no estado enquanto instituição soberana de normalização social, ou ainda melhor, como estrutura de institucionalização da sacralidade sobre conceitos de posse para garantia do desenvolvimento social a partir da divisão do trabalho.

Em Marx, podemos observar, que em um de seus últimos textos "crítica ao programa de Gotha" (2012), há a diferenciação clara sobre o Estado como um movimento separado da sociedade civil, que, ao mesmo tempo, institucionaliza a propriedade como forma de diferenciação entre corpos, em termos marxianos, como divisora de classes, todavia, tal propriedade privada é utilizada de forma estratégica, uma vez que a propriedade que dá origem a proteção estatal necessária para garantia da produção e reprodução do trabalho está intimamente ligada com a propriedade de corpos sobre outros corpos.

A regulamentação, ou a normativização, das relações sociais só através de uma análise superficial, ou puramente formal, se revela como homogênea e totalmente jurídica. Efectivamente, sob este ponto de vista, existem diferenças muito flagrantes entre 
os diversos domínios das relações humanas. (...) É precisamente no direito privado que o pensamento jurídico se move com a maior liberdade e segurança onde suas construções se revestem da forma mais acabada e harmoniosa (PASUKANIS, 1972, p. 68).

Dessa forma, observa-se que os gestos de diferenciação estatal para a proteção da propriedade privada torna-se um estatuto de contradição em que garante-se as liberdades individuais mas utiliza a propriedade como fórmula de definição quanto a atividade como método de manutenção da força de trabalho, de toda forma não há como sustentar a manutenção da instituição estatal à sociedade civil, uma vez que a derivação da posse de corpos é abolida pelo próprio estado, que, da mesmo forma, necessita de tal método para garantir-se como modelo sacrificial do soberano, como forma de reprodução ideológica a partir de sua gênese.

Em outras palavras, o Estado é existente sem o Soberano, entretanto, a institucionalização da propriedade privada é o elemento sacrificional resultante da violência soberana para sua existência.

Que por "Estado" entende-se, na verdade, a máquina governamental ou o Estado, na medida em que, por meio da divisão do trabalho, forma um organismo próprio, separado da sociedade, já o demonstram estas palavras: “O Partido Operário Alemão exige, como base econômica do Estado, um imposto único e progressivo sobre a renda etc." (MARX, 2012, p. 44).

Outra contradição que deixa mais aguda a contradição entre o Estado moderno analisado por Marx e a sociedade civil é, justamente, a incompletude sobre seus próprios conceitos de liberdade e individualização e a necessidade de poder sobre a sociedade civil, ou seja, por exemplo, a necessidade da formalização do divorcio, ou algum outro ato da sociedade civil que faz-se necessário ocorrer pela democracia liberal, que tem-se como manifestação do Estado como um particular garantidor das liberdades individuais.

Mais uma vez encontramos o reflexo do mitologema do soberano no modelo de Estado, assim como a função do biopoder, o Estado, que por meios ideológicos institucionalizados se mantém distante da sociedade civil, para garantir as supostas liberdades e individualizações necessita, formalmente, interferir nas relações sociais de forma que os contratos da sociedade civil tenham validade formal. 
A interferência da democracia liberal na forma do Estado à sociedade civil não é apenas uma contradição, mas é uma falha sobre o mascaramento da necessidade de manutenção do poder do Soberano sobre o corpo.

O Estado não necessita agir sobre o corpo, ou no caso da discussão marxista, na sociedade civil, mas a gênese do soberano que necessita manter o homem sacro no cerne de cada cidadão, precisa da manutenção de seu poder de forma violenta, ou seja, há necessidade do Estado como instituto do Soberano para que haja estatilização ideológica de sua gênese que, se desvelada, encontrase na formação da vida nua.

O Estado moderno, em Marx, é o símbolo da separação entre indivíduo e Estado, mas ao mesmo tempo é a união entre povo e soberano, o movimento individual justifica os contratos e afasta a instituição, mas a união dos corpos forma o soberano em sua égide de existência.

$\mathrm{Na}$ monarquia, por exemplo, este fato particular, a constituição política, tem a significação do universal que domina e determina todo o particular. Na democracia o Estado, como particular, é apenas particular, como universal é o universal real, ou seja, não é uma determinidade em contraste com os outros conteúdos. Os franceses modernos concluíram, daí, que na verdadeira democracia o Estado político desaparece. O que está correto, considerando-se que o Estado político, como constituição, deixa de valer pelo todo (MARX, 2010, p. 51).

Mais uma vez é necessário frisar que há uma diferença capilar entre a soberania e o Estado, justamente porque o Estado como se encontra após a revolução francesa e se mantém medularmente ainda no pós Segunda Grande Guerra, em razão da manutenção da democracia liberal - no entanto hodiernamente universalizada pela globalização - trabalha como garantidor da propriedade privada, em outras palavras da desvinculação do sujeito ao Estado, todavia, age sobre o sujeito enquanto povo, por estar relacionado diretamente à violência do poder soberano, que se identifica com a união de corpos, como fundamento de seu sacrifício de fundação.

Na essência do Estado moderno encontra-se a soberania, pois o poder fundamenta-se nela. O estado fundamenta a autonomia da soberania sobre um caráter de utilização de um conceito sacro, como a propriedade privada em seu âmago de dominação de corpos objetivados, e o institucionaliza como direito, 
garantindo a individualização, porém garantindo a violência no que tange a sociedade civil como povo, ou melhor, como união de corpos, que tem em si mantidos a sacralidade, porém com autorização de cidadania como fórmula de manutenção de poder.

Assim, a soberania, a essência do Estado, é aqui, primeiramente, considerada como uma essência autônoma, é objetivada. Depois, compreende-se, esse objeto deve se tornar novamente sujeito. Mas, então, esse sujeito aparece como uma autoencarnação da soberania, enquanto que a soberania não é outra coisa senão o espírito objetivado dos sujeitos do Estado (MARX, 2010, p. 44).

Para que o Estado possa corrigir sua contradição sobre sua existência e a existência da sociedade civil enquanto método democrático liberal deve haver a exclusão do povo, como movimento de resolução de contradições, entretanto é no povo que o soberano encontra seu fundamento de existência, uma vez que a sacralidade permanece como estrutura de manutenção de poder.

Imaginar o Soberano sem corpos é imaginar que o poder violento não se representa nos interesses de outros corpos, ou seja, o Estado moderno que Marx vê como contraditório encontra em si mesmo a vinculação da violência. É na contradição que os aparelhos ideológicos veem a necessidade manutenção do poder disciplinar, para que haja possibilidade de reprodução da força de trabalho, delimitação dos espaços de poder, concentração dos meios de produção, todos como fórmula de garantia da propriedade privada pela força estatal, mesmo que tais conceitos apareçam como contradições em termos para a garantia dos direitos individuais, há necessidade de manutenção dos corpos para existência do poder soberano, em sua gênese de violência originária.

O Estado se abole: no primeiro movimento e em um de seus significados, o desvanecimento do Estado consiste em uma consequência lógica e natural da contradição que o define. Para que o Estado moderno possa fazer face à impotência que configura sua existência ele deve abolir a sociedade civil ou 'esfera da vida privada contemporânea'. Para tanto, porém, ele deverá abolir a si mesmo, uma vez que o Estado moderno só existe enquanto Estado pela relação de antagonismo que trava com a sociedade civil (POGREBINSCHI, 2009, p. 49).

É na eliminação dos gestos de diferenciação, ou seja, no processo de extinção da divisão do trabalho que causa a consequente extinção das 
divisões de classes, que são oriundas de tais diferenciações baseadas em conceitos violentos que Marx indaga se "significa que após a derrubada da antiga sociedade haverá uma dominação de classe culminando um novo poder político? Não" (MARX, 1984, p. 193).

É justamente na autoridade política que o estado moderno se concentra, na utilização da estatialização, ou seja, na garantia de métodos de violência soberana para a manifestação do poder.

Certamente, Marx, especialmente na obra A miséria da filosofia (1984), após tomar o conceito de consciência geral do proletariado, se preocupa em afirmar sobre a institucionalização do modelo estatal como fórmula de contradição entre garantia e ação. Porém, não é na forma estado, como Marx estatuiu, que se concentra o poder violento e sim no Estado como fórmula de institucionalização da sacralidade soberana, ou seja, da manutenção ideológica do poder como forma de dominação e alienação dos corpos que se mantem com a vida nua, mas que o Soberano define seu afastamento.

Neste ponto pode-se pensar nos meios do rompimento ao Soberano a fim de que a violência sacralizada não atinja mais os corpos como fórumla de mito. Dessa forma, a busca deve sempre levar em consideração a ideia trazida no tópico anterior do rompimento geral com o mito, ou seja, a ideia de revolução ao Estado, principalmente a partir do ponto de vista marxista não será vista aqui como uma quebra institucionalizada, mas sim uma abolição a gênese soberana, como o trabalho investiga.

Certamente, entre os marxistas, se tem, após a noção de consciência de classe, a relação com a ditadura do proletariado, entretato, tal conceito apresenta muitas má interpretações, principalmente levando em consideração as poucas vezes que Marx tratou do tema, principalmente quando se toma a ausência do Estado em um debate com os anarquistas.

Marx jamais conceitualiza a ditadura do proletariado de forma relacionada à manutenção (seja ela parcial ou temporária) do Estado e tampouco de forma a negar que ele desapareça totalmente. Na verdade Marx jamais efetivamente conceitualiza a ideia de ditadura do proletariado em termos precisos e explícitos que permitam fazer tal relação. O sentido da ideia de ditadura do proletariado é mal entendido (POGREBINSCHI, 2009, p. 87).

Nesse sentido, importa pensar em uma supremacia dos vencidos a partir de uma ideia de união governante para além do Soberano. Como importa 
para o presente trabalho, o Estado é a institucionalização da sacralização do Soberano, ou seja, para a manutenção de seu mito sacrificial em relação aos corpos em seu seio, que apresentam a eterna relação com a vida nua, o Soberano mantém a existência da exceção sobre os corpos para sua existência, em outras palavras, o Soberano produz a vida nua para sua própria existência.

O Estado, por sua vez, é a representação institucionalizada do Soberano e, como observado nos primeiros tópicos do presente capítulo, instrumento primeiro de aparelhamento ideológico, para que tais corpos se mantenham disciplinados para uma relação de autonomia limitada.

Dentre tais aparelhamentos, os gestos de diferenciação, que em sua maioria apresentam-se ligados aos instrumentos de produção e reprodução do capitalismo, servem como modelo de alienação e delimitação da função social dos corpos dentro de um sistema em que o Estado se coloca como garantidor das liberdades individuais, porém é no soberano que os interesses das classes dominantes que se valem dos gestos de diferenciação são aplicados.

Podemos extrair do modelo de classes dominantes a verdadeira personificação do mito do soberano, ou seja, é na raiz dos aparelhos ideológicos que é necessária a existência do Soberano como garantidor do mito sobre o corpo e o Estado como reprodutor das relações internas do espaço de poder e da forma disciplinar.

Porém, quando se fala em um modelo de rompimento, ou melhor, revolução sobre tal estrutura de poder - em Marx, com a relação do proletariado - entende-se como uma reversão histórica, ou seja, a definitiva história dos vencidos sobre os vencedores, entretanto o risco é sempre a manutenção do mesmo aparelhamento, o que forma o efeito cíclico da história dos vencedores.

Para isso resta-nos pensar em uma ideia de Estado para além do Soberano, ou seja, a união dos vencidos, utilizando-se da violência pura benjaminiana, a partir de uma ideia de governança democrática. E é justamente em tal governança que podemos entender uma noção de estado não institucionalizado, apenas um modelo de acolhimento dos vencidos perante um modelo internacionalizado da política moderna.

É justamente na questão de Marx nunca haver abordado diretamente a questão da ditadura do proletariado que podemos encontrar a possibilidade da governanças dos vencidos e, consequentemente, na possibilidade de um Estado, com democracia presente, para além do soberano, ou seja, um estado não vinculado ao mitologema sacrifical, um estado sem a noção de bando, 
tampouco a aparelhagem ideológica.

O proletariado utilizará sua supremacia para arrancar, pouco a pouco, todo o capital à burguesia, centralizando os instrumentos de produção nas mãos do Estado, ou seja, do proletariado organizado enquanto classe governante, e para aumentar o mais rápido possível o total das forças produtivas (MARX; ENGELS, 2008, p. 59 - grifo nosso - tradução livre do autor $\left.{ }^{6}\right)$.

É justamente na organização do que Marx chama de proletariado enquanto classe governante que encontramos a possibilidade de um governo organizado a partir do resgate histórico dos vencidos. A partir da noção de que para além do Estado existe uma soberania que decide sobre a exceção, não apenas dos direitos estatais, mas sim do próprio corpo, como mito de fundação do poder violento, que se pode entender a possibilidade de um modelo "estatal" ou seja, uma governabilidade do até então oprimidos.

É na noção de uma estrutura ideológica das formações sociais, ou ainda, das contradições entre os modelos de Estado hodiernos e a sociedade civil, que se pode perceber que tal estado é apenas a instrumentalização do poder mitológico sacrificial.

Dessa forma, é possível, ainda em termos marxianos pensar em uma democracia real, que englobe interesses a partir do mesmo resgate histórico dos vencidos, ou seja, uma democracia desvinculada dos interesses de produção e reprodução das forças de trabalho, como garantia da propriedade privada e, consequentemente, a necessidade de manutenção dos corpos em um modelo de disciplina e garantia de interesses ideológicos.

Não se fala aqui da democracia liberal, por óbvio, se fala de uma democracia baseada na consciência, que Marx e Engels buscam na ideia de união dos trabalhadores, porém, no modelo mítico do soberano que nos encontramos, onde há uma necessidade universalização de "direitos impostos", pode ser buscada a partir da reversão dos conceitos de manutenção da história dos vencedores.

\footnotetext{
${ }^{6}$ No original: "Das Proletariat wird seine politische Herrschaft dazu benutzen, der Bourgeoisie nach und nach alles Kapital zu Entreissen, alle Produktionsinstrumente in den Händen des Staats, d.h. des als herrschende Klasse organisierten Proletariats, zu zentralisieren und die Masse der Produkitionskräfte möglichst rasch zu vermeheren".
} 
Não estamos falando de uma democracia real em que a Europa apressada em adotar e a qual consiste em uma democracia bastante especial, diferente de todas as democracias anteriores. Estamos falando sobre uma democracia bastante diferente, que representa um meio-termo entre as democracias gregas, romanas, americana e francesa. Em suma, estamos falando sobre o conceito de democracia. Não estamos falando sobre as matérias que pertencem ao século XIX, e que são más e efêmeras, mas sobre categorias que são eternas e que existem antes das " montanhas terem sido criadas". Em suma, nos não estamos discutindo aquilo sobre o que se tem falado, mas algo bem diferente (ENGELS, 1845 - tradução livre do autor ${ }^{7}$ ).

Por conseguinte, a noção da democracia baseada na história dos vencidos é basicamente uma reestruturação do modelo histórico de poder, ou seja, um rompimento com qualquer tipo de mito que sustente a ideia de poder.

Em Marx, principalmente em suas críticas à Hegel, há uma relação interessante da real democracia com a ideia da monarquia, ou seja, a monarquia como expressão da vontade superior, que se concentra em um mito divinista, se traduz na exclusão do mito e na elevação do interesse centralizado dos corpos, não mais observados do ponto de vista da sacralidade, mas do ponto de vista da autonomia.

A representação que a monarquia buscava a partir de um bem maior a ser seguido, a partir de ideias teológicas pode ser considerado a partir do bem maior da autonomia dos indivíduos enquanto movimento. Da mesma forma que o Estado age para garantia individual e o Soberano, por traz, necessita da unidade entre corpos disciplinados, a democracia, age sobre indivíduos organizados em um movimento uno, qual seja, a ideia de consciência atingida pelo rompimento mítico do poder violento.

Mais uma vez, resgata-se a ideia de Estado para além do Soberano, com uma ideia de constituição da autonomia, não como em um espaço bakininiano, mas em uma possibilidade de unidade de governança pela autonomia, ou seja, um modelo estatal que não se vincula à violência mítica do

\footnotetext{
${ }^{7}$ No original: "We are not talking about real democracy which the whole of Europe is hastening to embrace and which is a quite special democracy, different from all previous democracies. We are talking about a quite different democracy which represents the mean between Greek, Roman, American and French democracy, in short about the concept of democracy. We are not talking about the things which belong to the nineteenth century, and which are bad and ephemeral, but about categories which are eternal and which existed before "the mountains were brought forth". Briefly, we are not discussing what is being talked about but something quite different".
} 
soberano nascido da função ideológica da violência, melhor expressada pelo termo alemão Gewalt, uma vez que se concentra a violência e o poder em um conceito único de interpretação.

\section{Conclusão}

Outrossim, a democracia baseada em uma consciência de classe que se supera a partir do resgate histórico dos vencidos, se coloca como a união de indivíduos em um método de movimento socialmente vinculado. Ou seja, a autonomia do individuo é garantida pela possibilidade de uma análise histórica dos interesses até então protegidos pela forma violenta, o que restaria entender que toda a governança não se nortearia por conflitos, mas por interesses de movimento.

Ademais, o intuito de tal análise se concentra na ideia de que é possível pensar um Estado para além do mito violento do soberano, da mesma forma que se faz possível pensar em governança sem poder, mas substituindo tais conceitos, principalmente pela finitude da ideologia, pela autonomia do sujeito inserido em um movimento consciente de sua história que o coloca em posição de opressão.

Da mesma forma que, mesmo o decisionismo não sendo a regra dos estados, este se manifesta tanto nos atos de guerra, como nos discursos afirmativos perante as crises do normativismo e, ainda que não se manifeste suspendendo o direito a partir da decisão de um só homem, o Soberano decide em sua fundação sobre a exceção sobre o corpo, e a vida nua permanece interna em todo cidadão politicamente reconhecido, sendo que este está sempre a mercê de seu próprio espaço de anomia e a consequente decisão soberana sobre sua vida, em outras palavras, todo corpo, sob a relação de poder político vive em um permanente estado de exceção, que apenas aguarda sua suspensão que se manifesta a partir do próprio corpo, não mais de uma decisão específica, mas da renuncia tácita ou expressa de um indivíduo que, sob sua liberdade imposta universalmente, corre sempre o risco de se perder no amalgama ideológico e ser levado, por sua própria vontade que não pode controlar - por consequência da violência do próprio sistema - a sua exclusão de sua condição de humanidade. 


\section{Referências}

AGAMBEN, Giorgio. Estado de Exceção. Tradução Iraci D. Poleti. São Paulo: Boitempo, 2004.

Homo Sacer: o poder soberano e a vida nua I. Tradução Henrique Burigo. Belo Horizonte: UFMG, 2007.

O sacramento da linguagem. Tradução de Severino José Assman. São Paulo: Boitempo, 2011.

. Profanações. Tradução de Severino José Assman. São Paulo: Boitempo, 2007.

O que resta de Auschwitz: arquivo e testemunha. Tradução de Severino José Assman. São Paulo: Boitempo, 2008.

BENJAMIN, Walter. Crítica da violência. In: BENJAMIN, Walter. Escritos sobre mito e linguagem. Tradução de Ernani Chaves. Rio de Janeiro: 34, 2011.

O capitalismo como religião. Organização Michel Löwy; tradução Nélio Schneider; Renato Ribeiro Pompeu. São Paulo: Boitempo, 2013.

Sobre arte, técnica, linguagem e política. Lisboa: Relógio D'Água Editores, 1992.

CORREAA, Murilo Duarte Costa in Captura Críptica: direito política, atualidade. Revista Discente do Curso de Pós-Graduação em Direito, n.2, v.2. (jan/jun. 2010). Florianópolis: Universidade Federal de Santa Catarina, 2010.

ENGELS, Friedrich. The festival of Nations in London. In: MECW, 1845. Disponível em <http://hiaw.org/defcon6/works/1845/12/01.html> acesso em: 5 de julho de 2015.

GIACOIA JÚNIOR, Oswaldo. Entre a regra e a exceção: fronteras da racionalidade jurídica. In: Gramática dos direitos fundamentais. PADILHA, Norma Sueli; NAHAS, Thereza Christina; MACHADO, Ednilson Donisete (org.). Rio de Janeiro: Campus Jurídico, 2010. 
. Foucault. In: Em tempo, Marília, v6, p.9-19, 2014.

Notas sobre direito e violência. In: Kriterion. Belo Horizonte, n. 118, p. 267$308,2008$.

O discurso e o direito. In: FONSECA, R. M. (Org.). Direito e discurso: discursos do direito. p. 89-101. Florianópolis: Fundação Boiteux, 2006.

Violência e racionalidade jurídica: sobre a potência dos meios. Revista Brasileira de Estudos Políticos | Belo Horizonte | n. 108 | pp. 243-291 | jan./jun. 2014

MARX, Karl. O Capital - edição resumida por Julian Borchardt. Tradução de Ronaldo do Alves Schmidt. 7. ed. Rio de Janeiro: Guanabara, 1982.

. ENGELS, Friedrich. A ideologia alemã. Tradução Luis Claudio de Castro e Costa. São Paulo: Martins Fontes, 1998.

A miséria da filosofia. Tradução José Paulo Netto. São Paulo: Global, 1984.

Crítica da filosofia do direito de Hegel. Tradução de Rubens Enderle e Leonardo de Deus. São Paulo: Boitempo, 2010.

Crítica do Programa de Gotha. Seleção, tradução e notas Rubens Enderle. São Paulo : Boitempo, 2012.

ENGELS, Friedrich. Manifest der Kommunistischen Partei: Proletarier aleer Länder, vereinigt euch. Lausanne: Metalibri, 2008.

PASUKANIS, Evgeny Bronislavovic. A teoria geral do direito e o marxismo. Coimbra: Perspectiva Jurídica, 1972.

POGREBINSCHI, Thamy. O enigma do político: Marx contra a política moderna. Rio de Janeiro: Civilização Brasileira, 2009.

RAMIRO, Caio Henrique Lopes. Heurística do poder e perspectivas críticas ao Estado de Direito: uma leitura a partir de Walter Benajmin. P. 239-254. In Revista de Informação Legislativa, $\mathbf{n}^{0}$ 198. Brasília: Secretaria de editoração e publicações, 2013. 